\title{
Household Savings in Japan Revisited
}

\author{
Yukinobu Kitamura, Noriyuki Takayama and Fumiko Arita
}

September 2000

Revised November 2000

\begin{abstract}
This paper investigates the household saving behavior by different cohorts with various household characteristics in Japan. Pooling the National Survey of Family Income and Expenditure in 1984, 1989 and 1994, the cohort analysis finds a substantial behavioral difference in the baby-boomer generation in Japan after 1989. As this generation is the largest demographic group, this finding provides valuable information to policy makers, especially in terms of intergenerational equity.
\end{abstract}

Keywords: savings, life-cycle, cohorts, and social security wealth. JEL classification: D91, E2, E21, H55.

\footnotetext{
* This paper was prepared for the Joint TMR-ESF-SFB 504 Conference on Savings, Pensions, and Portfolio Choice, held in Deidesheim, Germany, April 6-9, 2000. We are grateful to the organizers of the conference, especially to Drs Axel Börsh-Supan and Angelika Eymann of Universitaet Mannheim for inviting us to this conference. We are very grateful to Dr Charles Yuji Horioka for his constructive comments on the early draft. We are also grateful to Michiko Baba for her efficient and skillful data processing. Corresponding address: Noriyuki Takayama and Yukinobu Kitamura, Hitotsubashi University, Institute of Economic Research, Naka 2-1, Kunitachi, Tokyo 186-8603, Japan. Fumiko Arita, Toyo Eiwa Women's University, Department of Social Science, Miho-machi 32, Midori-ku, Yokohama, 226-0015, Japan. E-mail address: Noriyuki Takayama: takayama@ier.hit-u.ac.jp, Yukinobu Kitamura: kitamura@ier.hit-u.ac.jp, Fumiko Arita: arita@toyoeiwa.ac.jp. .
} 


\section{Introduction}

It has been six years since our publication on household savings in Japan.

Our previous publication made use of the large micro data, the National Survey of Family Income and Expenditure (NSFIE), over the period of 1979-1989 (see Takayama and Kitamura (1994)). Now that the micro data from the 1994 NSFIE has become available among academic users, we would like to add new information to our previous work and uncover new facts that have emerged after the burst of the bubble economy.

Many papers have been written on the topic of Japanese household saving. Among them, Hayashi (1997) is a landmark of this literature. Chapter 10 of Hayashi (1997) provides an excellent account of recent literature and evidences on Japanese saving. He identifies key stylized facts; (1) Japan's saving rate is not as high as commonly thought, and (2) the accumulation of wealth by Japanese households starts very early and lasts until very late in life, with unconsumed wealth transferred to the next generation in the form of bequests. As to the second point, Hayashi, Ando, and Ferris (1988) argues that the bulk of intergenerational transfers take place in the form of bequests and that bequests come not only from the independent (nuclear) old, but also from the pool of extended families that seem to accumulate wealth regardless of the parents' age. Barthold and Ito (1992), using bequest tax filing information, shows that 
about one-third to one-half of household assets are obtained by bequests in Japan. It implies that the old households do not dissave enough and leave sizable bequests, intended or not. Takayama and Kitamura (1994) also finds some evidence of substantial intergenerational transfers from the NSFIEs. Ohtake (1991) argues that bequests are motivated by selfishness rather than by altruism. From these studies, we conclude that intergenerational transfers do occur at a substantial magnitude, no matter what motivation lies behind it.

Horioka $(1990,1993)$ provide another good survey of the literature from the viewpoint of different motives for saving. The author has identified more than 30 factors. Horioka and Watanabe (1997) also conducted empirical investigation of saving motives using a micro data from a Japanese government survey. Horioka finds that net saving for retirement and precautionary motives are of dominant importance. Using a different data set, Ohtake and Horioka (forthcoming) discovers that retirement and housing motivations are of importance. Motivation for the acquisition of owneroccupied housing remains strong and it promotes high saving, especially because of limited mortagage markets and high down-payment requirements (i.e. the presence of liquidity constraints). Hayashi, Ito and Slemrod (1988) investigates the effects of tax incentives and down-payment requirements on household's tenure choice and on saving 
behavior in the U.S. and Japan by simulation method. The result is that these factors do not offer a complete explanation of the large gap between the saving rates of the two countries largely because of institutional differences in the typical down-payment ratio and tax incentives.

This paper will shed light on the saving behavior by different cohorts with various household characteristics. This is because (1) generational (cohort) aspects of saving behavior is relatively unexplored in Japan, and (2) plurality of saving behaviors is attributable to various household characteristics, not to saving motives as such. We construct the cohort data by pooling a total of 110,194 households, after eliminating outliers in the 1984, 1989, and 1994 NSFIEs.

As age effect, time effect, and cohort effect interact with each other, it is difficult to separate them individually. Therefore we need to go beyond tabulation and summary statistics as shown in Takayama and Kitamura (1984), to use some statistical methods to overcome these difficulties and to identify the main driving forces of household savings behavior in Japan. Full econometric analyses are not conducted here and will be reported in the forthcoming conference volume of international comparisons of household savings from Academic Press. 


\section{The Data}

Since 1959, the NSFIE has been conducted every five years to reveal levels of income, consumption and household assets, their structure and distribution, as well as the differences among regions. All these analyses are done through the investigation of two key areas: family income and expenditure, and assets and liabilities in Japanese households. This survey is designed to sample over 50,000 households (54,000 in 1984, 59,100 in 1989, and 56,000 in 1994). Survey items include (1) family income and expenditure, (2) annual income, financial assets and liabilities, (3) major durable goods, and (4) attributes of households and their members, including housing conditions.

With a large sample size and wide coverage in items, the NSFIE is a treasure trove of information. It enables researchers to make detailed analyses according to various household characteristics ${ }^{1}$.

The data we use here are taken from the 1984, 1989, and 1994 NSFIEs for twoor-more person households ${ }^{2}$. In the previous study (Takayama and Kitamura (1994)),

\footnotetext{
${ }^{1}$ For details of the NSFIE, see Hayashi, Ando and Feris (1988).

${ }^{2}$ There is another set of survey for single-person households. The sample size is about 4900 . The data cleaning processes are as follows. (1) If head age is recorded as zero, then delete. (2) If disposable income is zero or negative, then delete. (3) If both saving and disposable income are negative, then delete (because saving rate cannot be defined properly). (4) If saving rate is less than $-10000(\%)$, then delete. (5) If values of disposable income, consumption, saving and saving rate are beyond 4 times of standard deviation of respective variable, then delete (elimination of outliers).
} 
monthly consumption data were converted into yearly data after taking seasonal fluctuations into account. As yearly income is originally given in the NSFIE, savings are calculated as yearly income minus taxes and social security contributions, minus yearly consumption.

The advantage of this approach is that internationally comparable yearly savings can be obtained, given most households smooth out their consumption-saving patterns over a year ${ }^{3}$. The disadvantage is in the need to estimate some crucial variables such as yearly consumption, yearly taxes, and social security contributions. The NSFIE contains information only for the three months from September through November. We have had to use external information from the Family Income and Expenditure Survey (FIES) for the other months' consumption. Also, taxes and social security contributions had to be calculated using information on household characteristics and yearly income provided in the NSFIE. Regrettably, these processes can be sources of errors in variables ${ }^{4}$.

\footnotetext{
${ }^{3}$ Of course, we cannot eliminate possibilities of purchasing large consumer durables and houses, which are rare events in all households. In such cases, yearly consumption can easily exceed yearly disposable income.

${ }^{4}$ For example, conversion from three monthly to yearly consumption is done simply through multiplying common (average) annual conversion factors for 10 major expenditure items by three monthly respective consumption. Needless to say, each household has different expenditure patterns over a year. It may not be appropriate to apply common (average) annual conversion factors for households with different
} 
The most discussed data problem with the NSFIE is the sample selection bias with old households. The problem goes as follows. Because of the prevalence of the extended family for example, in 1994, $17.5 \%$ of all households were extended family and $30.6 \%$ of all households have household members aged above $65^{5}$. The existence of extended families implies that there are two categories of older people: those still maintaining an independent household (i.e. the independent old) and those living with children (i.e. the dependent old). Wealth and flow of savings for the dependent old cannot be observed directly because of no breakdown among family members in the NSFIE. When the true age profile of saving behavior is to be identified, we have to extract savings and wealth of dependent old from the extended families and add them to those of the independent old. As the economic status of the independent old is substantially better than that of the dependent old, the old age saving behavior would have a self-selection bias if we do not make such adjustments. Hayashi, Ando and Ferris (1988) suggests a method of removing this bias by comparing nuclear families and extended families whose younger generation is similarly aged. We find however characteristics (e.g. different demographic compositions and different income groups). Furthermore, to calculate annual taxes and social security contributions is very difficult, given numerous exemptions, deductions and allowances.

5 This implies that $13.1 \%$ of the elderly live their own and this trend has been increasing over time. Sooner or later, of all people age above 65 , more than half of them live independently from their children, 
that this method needs to be refined due to insufficient control of household characteristics to carry out statistical matching between nuclear and extended families ${ }^{6}$. Takayama and Kitamura (1994) provides a complementary estimation method of intergenerational transfers to Hayashi, Ando and Ferris (1988).

It is quite important to adjust this sample selection bias, if the main research issues are concerned with the saving and wealth accumulation behavior of the old households or intergenerational transfers from the old to the young households.

The purpose of this paper is somewhat different from these, and is to identify the cohort effects on savings, especially those of the baby-boomer cohort by using statistical methods. We decide not to adjust our data based on two reasons. First, we would like to avoid any arbitrary statistical adjustments as discussed above (namely a seasonal adjustment to derive yearly savings and a sample selection bias of the old households) which may create artificial errors in variables. We will use the raw data from the NSFIEs. Second, we find ample evidences of rapidly decreasing number of extended families, thus, it may be quite misleading to excessively stress the importance given a rapid decrease in number of children and generous social security benefits.

${ }^{6}$ For example, the extended families are prevalent in self-employed households living in the rural areas, while the nuclear families are prevalent in employees' households living in the big cities. A simple comparison between the two only adjusting age cohorts is quite misleading, because this comparison may reflect differences in region, occupation, and social values. 
of extended family in Japan (see Table 2 below). Furthermore, this paper is not directly concerned with the old households as it were, but with the younger households and cohorts.

Comparable analysis using the yearly data and methodological work to remove sample selection bias are left to our future work.

\section{Cohort Analysis of Saving Behavior}

For most of the interesting questions about saving and the life-cycle, it is necessary to track individuals over time and to observe the changes in consumption, income, and savings as people age. Of course, the best possible data set for such analysis is the panel data in which each individual household can be tracked over time. But such data are rarely available in Japan, especially for an economy-wide official survey.

As a second-best solution, we can construct cohort data from an independent survey such as the NSFIE. In this paper, cohorts are grouped into five-year intervals of birth. Since the NSFIE itself is surveyed every five years, this grouping is done for the sake of convenience. In other words, the 25-29 age bracket in 1984 for example, is linked with the 30-34 age bracket in 1989 and the 35-39 age bracket in 1994 to form the cohort of 1955-1959 birth year. Longitudinal profiles created this way are called 
synthetic cohorts.

Table 1 shows number of households by cohort over the different surveys.

Except for a very old cohort (i.e. Cohort 1) and very young cohorts (i.e. Cohorts 8 and 9), population in each survey remains, more or less, constant which reflects the demographic distribution of total population in Japan.

*** Table 1 about here ***

Table 2 reports the average number of household and working members by cohorts. It is necessary to check whether the basic household characteristics remain stable.

$$
\text { *** Table } 2 \text { about here } * * *
$$

Average number of household members decreases over time for the older cohorts (i.e. cohorts1-6) and increases over time for the younger cohorts (i.e. cohorts 79). Apart from differences in the sample base, it seems quite natural that members of older cohorts decrease as their children become independent and spouses pass away, and that members of younger cohorts increase as the couple has children and their parents merge in. But, in general, Table 2 implies that the average Japanese household is nuclear family, not extended family (e.g. three generations cohabitation). The lower panel of Table 2 shows the average number of working members. Up to cohorts 1 to 3 , 
the average working members decrease due to the fact that their children become independent and spouses pass away. But as to cohort 4 to cohort 6 , average working members increase while average household members decrease in the upper panel. It may be the case that more house wives keep working at the their age of 30 s and 40 s in recent years.

Fig.1 illustrates age profile of saving rates in the pooled 1984,1989, and 1994 NSFIEs data. The upper line represents the standard measure of saving rates (=savings divided by disposable income) by age, the lower line indicates the average of individual saving rates. The trend remains more or less the same until age 60 , then the two lines diverge significantly as income and wealth distributions get worse after age 60 . Indeed, unlike a typical average saving pattern over a lifecycle, a large pooled microeconomic survey indicates the plurality of saving behaviors among 110,194 households. Among them, 81,721 households have positive savings while 28,473 households have negative savings. Here, negative savings imply that such households consume more than their disposable income. They are financed either by past savings or consumer loans.

*** Fig. 1 and Fig. 2 about here ***

Households with negative savings therefore, do not face any liquidity 
constraints as is evident from zero-coefficient on disposable income in our saving regression (the main result will be reported in the forthcoming conference volume). In addition, not all households with positive savings are liquidity constrained as the average propensity to save of these households is quite high in our regression model ${ }^{7}$.

Fig.2 illustrates the average saving rate by cohorts. The saving pattern remains stable up to age 54 , and declines steadily afterwards. A noticeable point is that saving rate of the baby-boomer cohort dropped in 1994 while that of most neighboring cohorts went up.

Table 3 shows summary statistics of disposable income, savings and saving rate by cohorts. Table 3 indicates that cohort 4 is the highest saver because this cohort reaches the highest point in the wage-profile, i.e. age 55-59. But if we look at saving rate, the level is more or less, the same for the cohorts 4-9. The saving rate of the oldest cohort is substantially lower than the other cohorts. This pattern corresponds with Fig.2.

$$
* * * \text { Table } 3 \text { about here } * * *
$$

\footnotetext{
${ }^{7}$ Ban and Takagi (2000) use the 1984,1989 and 1994 NSFIEs to construct synthetic panel data and examine the effect of liquidity constraint on household consumption. They obtain no evidence of liquidity constraint among the Japanese households. Their strong result may stem from a functional form they use. Further elaboration is needed.
} 
In order to identify whether each cohort belongs to the same population, it is natural to conduct analysis of variance (ANOVA). Table 4 reports ANOVA for saving rate against cohort and year ${ }^{8}$ Although variance of savings rate against cohort differs from each other, that against year is much smaller in general. Regression result of the same ANOVA indicates that values and its significance of coefficients by different cohorts are quite heterogeneous (i.e. cohort 1-3 versus cohorts 4-9) and that values of coefficient by year turn out insignificant. No sigh of time effect is found. Table 5 shows results ANOVA against cohort over all years (1984-94) as well as in each year. ANOVA in 1984-94 indicates that the main source of heterogeneity comes from cohorts 1-3. Cohorts 4-9 seem quite homogeneous over all years. To be more precise, the degree of heterogeneity is similar. However, if we look at ANOVA each year carefully, there are some signs of heterogeneity even among cohorts 4-9. In 1984, cohort 1 was the only outlier, in 1989, cohorts 1-2 and cohorts 6-7 become outliers and in 1994, cohorts 1-3 and cohort 6 were the outliers. An interesting finding here is that cohort 6 , the baby-boomer generation, starts behaving differently as early as in their 40s in 1989 and 1994.

*** Table 4 and Table 5 about here ***

\footnotetext{
${ }^{8}$ By focusing saving rate, we can avoid price change effect, given price change affects, more or less, in
} 
The baby boomer generation deserves a special attention because they consist the largest demographic group. We need to investigate further to identify their heterogeneous behavior with econometric tests ${ }^{9}$.

It is noteworthy that in the U.S., the unprecedented economic boom in the 1990s has enabled the boomer generation to accumulate their wealth (see Sterling and Waite (1998)) in the forms of real estate, pension funds, and stocks. Conversely, the protracted Japanese economic recession in the 1990s has made very little room for the boomer generation to accumulate their wealth for after-retirement by themselves and through firms' retirement severance pay funds ${ }^{10}$.

\section{Construction of Social Security Wealth}

Another important issue in household saving is to identify whether or not the social security system affects household saving. This question was originally raised by Feldstein (1974) and extended by many authors. In case of Japan, Takayama (1992a,b) conducted an econometric estimation of consumption expenditure, using the

the same way on savings and disposable income.

9 This task is left to the conference volume of international comparisons of household saving from Academic Press.

${ }^{10}$ We have to be careful about the conceptual differences of the baby boomer generations in the U.S. and in Japan. In the U.S., the baby boomer includes those who were born from 1946 to 1968, while in Japan, 
present value of public pension benefits (GSSW) as one of the explanatory variables in the 1979 and 1984 NSFIE. Estimated values of the parameter for GSSW are significantly positive. For workers' households, the figures are about $1.2 \%$ in 1979 and $2.4 \%$ in 1984 , implying that the presence of social security wealth caused annual consumption expenditure to increase $1.2 \%$ and $2.4 \%$ of GSSW in 1979 and 1984 respectively.

The model can be refined by allowing the effect of human capital variables to vary by age. The presence of social security wealth is estimated to increase 1984 consumption expenditures of workers' households by about $1.5 \%$ of GSSW. This increase in consumption expenditure would be equivalent to $13.9 \%$ and $12.0 \%$ of disposable income in 1979 and 1984 respectively.

The Japanese public pension program increases working households' propensity to consume, viz., the evidence confirms the hypothesis that social security wealth discourages personal savings in Japan.

Note, however, that the public pension system has been changed many times and will be reformed again and again in the future. Benefits and contributions will be more closely balanced; the social security wealth of each individual will also be reduced 
in the near future by raising the normal retirement age to 65 or more and by decreasing real levels of monthly benefits. The future prospects of these reforms might have encouraged household savings ${ }^{11}$.

According to our framework, the following identity is defined.

Income $-($ tax and social security contributions $)=$ disposable income

$$
=\text { consumption and savings }
$$

Social security contributions are further divided into public pension contributions, health insurance, and other social insurance. Let us define discretionary savings as savings in the RHS of eq. (1) and mandatory savings as (public pension contributions public pension benefits + contributions to the severance pay fund + interests from social security wealth + interests from accumulated severance pay). For statistical simplicity, here we take mandatory savings simply as public pension contributions minus public pension benefits (i.e. net public pension contributions), and ignore contributions to the severance pay fund, interests from social security wealth, and interests from accumulated severance pay. Then, it is obvious from construction of eq.(1) that discretionary savings are negatively correlated with mandatory savings. In addition,

\footnotetext{
${ }^{11}$ Although we have not conducted a similar econometric analysis using the 1989 and 1994 NSFIE, high saving rates among those aged above 55, might be an evidence of precautionary savings due to uncertainty in the public pension system. See Takayama (2000a) for the latest public pension reform plan.
} 
we calculate the crude ratio between mandatory savings and discretionary savings for different age groups. The results are given in Table 6 .

$$
\text { *** Table } 6 \text { about here } * * *
$$

It is apparent that the ratio becomes significantly negative for those aged above 60 , i.e. cohorts 1-3. Cohort 1 in 1994 shows a substantially high positive value, which is because saving itself is negative, so that the ratio becomes positive. There is no surprise in the fact that cohort 1 in 1994 receives rather large net benefits. That is, mandatory savings do matter with the old households. The ratio becomes negative in overall average in 1989 and 1994. This implies that the balance of public pension system as a whole becomes negative.

In the near future, generous public pension benefits in Japan are to be reduced, while the contribution rate may be permanently frozen at the current level or be reduced through a partial shift of funding to a consumption-based tax. At the same time, we should encourage private initiatives including a private, personal saving account for retirement, through the use of powerful tax-incentives ${ }^{12}$. In addition, generational accounting results from Japan (see Takayama, Kitamura and Yoshida (1999) and Takayama and Kitamura (1999)) also indicate that we cannot afford to provide generous

\footnotetext{
${ }^{12}$ A Japanese version of $401 \mathrm{~K}$ plan is to be introduced in the near future. See Takayama (2000b).
} 
public pension benefits to the boomer cohort and that further public pension reforms would be inevitable, if the public pension scheme is to be kept running.

To construct social security wealth (SSW) as the mandatory savings, we need to use the baseline equation as follows,

$$
S S W_{t+1}=(1+\rho) S S W_{t}+\tau_{t}-b_{t}
$$

where $S S W=$ social security wealth, $\rho=$ internal rate of return, $\tau_{t}=$ public pension contribution, $b_{t}=$ public pension benefits .

First, the stream of public pension contributions can be calculated from ageearning profile multiplied by historical public pension contribution rates over the period of 1960-1999. Second, the stream of public pension benefits is to be adjusted annually with inflation and is added up to the average life expectancy (from 2000 to 2022). Third, we have to set $S S W_{t+R}=0$ such that the internal rate of return equates two streams; public pension contributions and benefits under the Pay-As-You-Go system. At the age of retirement, 60 in year 2000, SSW in Japan is estimated to equal 34.21 million yen and the nominal internal rate of return is $8.7 \%$ per year.

Given the average net financial assets (excluding $S S W$ ) for age 60-64 in 1994 was 20.42 million yen, the estimated SSW 34.21 million is very large indeed, although the actual $S S W$ is expected to be even larger than the estimated $S S W$. 
As is obvious, the $S S W$ includes a component of intergenerational transfers. If we assume that the market rate of return from investment was $5.5 \%$ in nominal terms per annum, and that the discount rate for the future $S S W$ will be $4.0 \%$, then, the estimated $S S W$ will go up to 50.92 million yen. This figure will be rather common in the Japanese sense. Consequently, the component of intergenerational transfers in the SSW will turn out to be as much large as 29.13 million yen, in this case.

$$
\text { *** Fig. } 3 \text { about here *** }
$$

\section{Conclusion}

Unlike the previous study of cross section analysis of the NSFIE in Takayama and Kitamura (1994), in this paper we observe the household saving behavior in Japan from a viewpoint of cohort profile.

Our findings are as follows. (1) In general, the cohort analysis indicates that the saving behavior changes after age 55 and that the cohort behavior is not so different among cohorts younger than age 54. It dose not imply homogeneity of younger cohorts, but the degree of heterogeneity is more or less the same among the younger cohorts. (2) However, after the 1989 NSFIE, The baby-boomer cohort, age 40-44, has already deviated from other younger cohorts. This phenomenon did not exist in the 1984 NSFIE when the baby-boomer cohort was age 35-39. (3) Estimated social 
security wealth $(S S W)$ under the Japanese environment, is as much as 50.92 million yen at the age of retirement. The component of intergenerational transfers in the $S S W$ is also very large.

The first point may be reflected by the fact that increase in heterogeneity after age 55 , especially after 60 , is mostly due to differences in lump-sum retirement severance payments or $S S W$. Variability of these benefits is much wider than that of regular monthly salaries as the firms' economic performances, welfare plans for retirement severance pay funds, and unions' bargaining powers differ substantially among firms and organizations.

The second point is that as the baby-boomer cohort is consisted of the largest demographic group, their behavior affects macroeconomic variables such as aggregate consumption, investment and income distribution.

This leads to the third point. When the baby-boomer generation reaches their late 50 s and early 60 s, variability of retirement severance payments or $S S W$ and that of intergenerational transfers will be much wider than now. Intergenerational equity issue will inevitably be focused on the baby-boomer generation. It is quite crucial to set up institutional arrangements concerning intergenerational equity (e.g. public and private pension schemes) before the baby-boomer generation reaches their retirement 
age. This task is left to our future research project.

\section{References}

Ban,K. and Takagi, S.(2000) "Synthetic Panel Data" in Matsuda, Y., Ban, K. and Yoshizoe, Y. (eds) Analytical Techniques of Microeconomic Data, Tokyo: NihonHyouron-sha (in Japanese), pp.284-303.

Barthold, T. and Ito, T.(1991) "Bequest taxes and accumulation of household wealth: U.S.-Japan comparison", in Ito, T. and Kruger, A.(eds) The Political Economy of Tax Reform, Chicago: The University of Chicago Press, pp. 235-90.

Feldstein, M.(1974) "Social Security, Induced Retirement and Aggregate Capital Accumulation", Journal of Political Economy, 82(5), pp.905-26.

Hayashi, F.(1997) Understanding Saving, Cambridge: The MIT Press.

Hayashi, F., Ando, A. and Ferris, R.(1988) "Life cycle and bequest savings: A study of Japanese and U.S. households based on data from the 1984 NSFIE and the 1983 Survey of Consumer Finance", Journal of the Japanese and International Economies, 2, pp.450-91.

Hayashi, F., Ito, T., and Slemrod, J. (1988) "Housing finance imperfections, taxation, and private saving: A comparative simulation analysis of the United States and Japan", Journal of the Japanese and International Economies, 2, pp.215-38.

Horioka, C.Y.(1990) "Why is Japan's saving so high? A literature survey", Journal of the Japanese and International Economies, 4, pp.49-92.

Horioka, C.Y.(1993) "Savings in Japan", in Heertje, A.(ed) World Savings: An International survey, Oxford: Blackwell.

Horioka, C.Y. and Watanabe, W.(1997) "Why do people save? A micro-analysis of motives for household saving in Japan”, Economic Journal, 107, pp.537-552.

Ohtake, F.(1991) "Bequest motives of aged households in Japan”, Ricerche Economiche, 45(2/3), pp.283-306.

Ohtake, F. and Horioka, C.Y.(forthcoming) "Saving motives in Japan", in Ishikawa, T.(ed) The Distribution of Income and Wealth in Japan, Oxford: Oxford University Press.

Sterling, W. and Waite, S.(1998) Boomernomics, New York: Balantine Books.

Takayama, N. (ed)(1992a) The Stock Economy (in Japanese), Tokyo: Toyo-Keizai.

Takayama, N. (1992b) The Greying of Japan: An Economic Perspective on Public 
Pensions, Tokyo: Kinokuniya and Oxford: Oxford University Press.

Takayama, N. (1998) The Morning After in Japan: Its Declining Population, Too Generous Pensions and a Weakened Economy, Tokyo: Maruzen.

Takayama, N.(2000a) "The Outline of the 1999 Pension Reform Bill in Japan", available on the website http://www.ier.hit-u.ac.jp/ takayama.index.html).

Takayama, N.(2000b) “An Outline of the Defined-contribution Pension Plan: Japan's Version of the 401(k) Plan", JETRO Investment News, no.21.

Takayama, N., Funaoka, F., Ohtake, F., Sekiguchi, M. and Shibuya, T.(1989) Household Assets and The Saving Rate in Japan (in Japanese). Keizai Bunseki, no.116 (September).

Takayama, N. and Kitamura,Y. (1994) "Household Saving Behavior in Japan", in Poterba, J.M.(ed) International Comparisons of Household Saving, Chicago: The University of Chicago Press. pp. 125-167.

Takayama, N., Kitamura, Y. and Yoshida, H. (1999) “Generational Accounting in Japan”, in Auerbach, Alan J., Kotlikoff, Laurence J. and Leibfritz, Willi. (eds) Generational Accounting Around The World, Chicago: The University of Chicago Press. pp. 447-469.

Takayama, N. and Kitamura, Y. (1999) "Lessons from Generational Accounting in Japan”, American Economic Review, 89 (2), pp.171-175. 
Table 1 N umber of Households by Cohort

\begin{tabular}{cccccr}
\hline \multicolumn{2}{c}{ Birth Year } & 1984 & 1989 & 1994 & \multicolumn{1}{c}{ Total } \\
\hline Cohort 1 & $(1920-24)$ & 1,514 & 1,520 & 2,352 & 5,386 \\
Cohort 2 & $(1925-29)$ & 2,940 & 2,783 & 2,797 & 8,520 \\
Cohort 3 & $(1930-34)$ & 3,705 & 3,748 & 3,394 & 10,847 \\
Cohort 4 & $(1935-39)$ & 4,557 & 4,443 & 4,142 & 13,142 \\
Cohort 5 & $(1940-44)$ & 5,775 & 5,575 & 5,468 & 16,818 \\
Cohort 6 & $(1945-49)$ & 6,363 & 6,682 & 6,326 & 19,371 \\
Cohort 7 & $(1950-54)$ & 4,934 & 6,356 & 6,560 & 17,850 \\
Cohort 8 & $(1955-59)$ & 2,067 & 4,230 & 5,527 & 11,824 \\
Cohort 9 & $(1960-64)$ & 347 & 1,974 & 4,115 & 6,436 \\
\hline Total & & 32,202 & 37,311 & 40,681 & 110,194 \\
\hline
\end{tabular}


Table 2 Average Number of Household Member and Working Member

Average Number of Household Members by Cohort

\begin{tabular}{|c|c|c|c|c|c|}
\hline \multicolumn{2}{|c|}{ Birth Y ear } & 1984 & 1989 & 1994 & Total \\
\hline Cohort 1 & $(1920-24)$ & 2.82 & 2.57 & 2.26 & 2.51 \\
\hline Cohort 2 & $(1925-29)$ & 3.24 & 2.79 & 2.48 & 2.84 \\
\hline Cohort 3 & $(1930-34)$ & 3.54 & 3.19 & 2.75 & 3.17 \\
\hline Cohort 4 & $(1935-39)$ & 4.05 & 3.58 & 3.12 & 3.60 \\
\hline Cohort 5 & $(1940-44)$ & 4.32 & 4.07 & 3.54 & 3.98 \\
\hline Cohort 6 & $(1945-49)$ & 4.28 & 4.38 & 4.04 & 4.24 \\
\hline Cohort 7 & $(1950-54)$ & 3.91 & 4.32 & 4.32 & 4.21 \\
\hline Cohort 8 & $(1955-59)$ & 3.14 & 3.81 & 4.20 & 3.87 \\
\hline Cohort 9 & $(1960-64)$ & 2.73 & 3.15 & 3.59 & 3.41 \\
\hline Total & & 3.86 & 3.79 & 3.58 & 3.73 \\
\hline
\end{tabular}

Average Number of Working Members by Cohort

\begin{tabular}{cccccc}
\hline \multicolumn{2}{c}{ Birth Year } & 1984 & 1989 & 1994 & Total \\
\hline Cohort 1 & $(1920-24)$ & 1.19 & 0.74 & 0.34 & 0.69 \\
Cohort 2 & $(1925-29)$ & 1.86 & 1.18 & 0.70 & 1.26 \\
Cohort 3 & $(1930-34)$ & 2.00 & 1.92 & 1.27 & 1.74 \\
Cohort 4 & $(1935-39)$ & 1.79 & 2.08 & 2.02 & 1.96 \\
Cohort 5 & $(1940-44)$ & 1.56 & 1.78 & 2.11 & 1.81 \\
Cohort 6 & $(1945-49)$ & 1.49 & 1.55 & 1.80 & 1.61 \\
Cohort 7 & $(1950-54)$ & 1.40 & 1.47 & 1.59 & 1.50 \\
Cohort 8 & $(1955-59)$ & 1.38 & 1.38 & 1.47 & 1.42 \\
Cohort 9 & $(1960-64)$ & 1.38 & 1.38 & 1.37 & 1.37 \\
\hline Total & & 1.60 & 1.58 & 1.54 & 1.57 \\
\hline
\end{tabular}




\section{Table 3 Summary Statistics by Cohort (yen)}

\section{Disposable Income}

\begin{tabular}{llllrc}
\hline \multicolumn{2}{c}{ Birth Year } & MEAN & SDV & \multicolumn{1}{c}{ MIN } & \multicolumn{1}{c}{ MAX } \\
\hline Cohort 1 & $(1920-24)$ & $257,359.93$ & $155,272.01$ & $6,716.67$ & $1,253,944.00$ \\
Cohort 2 & $(1925-29)$ & $320,134.65$ & $169,163.16$ & $2,697.00$ & $1,375,929.94$ \\
Cohort 3 & $(1930-34)$ & $375,652.20$ & $174,291.09$ & $16,051.67$ & $1,374,385.67$ \\
Cohort 4 & $(1935-39)$ & $421,403.00$ & $178,372.04$ & $7,233.33$ & $1,377,954.34$ \\
Cohort 5 & $(1940-44)$ & $412,563.81$ & $168,466.23$ & $12,550.00$ & $1,372,825.00$ \\
Cohort 6 & $(1945-49)$ & $374,860.17$ & $149,107.87$ & $18,768.00$ & $1,362,518.30$ \\
Cohort 7 & $(1950-54)$ & $345,371.33$ & $135,226.91$ & $15,000.00$ & $1,369,736.97$ \\
Cohort 8 & $(1955-59)$ & $325,974.60$ & $127,818.33$ & $25,855.00$ & $1,329,259.70$ \\
Cohort 9 & $(1960-64)$ & $313,509.52$ & $115,111.54$ & $22,250.00$ & $1,312,963.30$ \\
\hline
\end{tabular}

Savings

\begin{tabular}{llllrr}
\hline \multicolumn{2}{c}{ Birth Year } & \multicolumn{1}{c}{ MEAN } & SDV & \multicolumn{1}{c}{ MIN } & \multicolumn{1}{c}{ MAX } \\
\hline Cohort 1 & $(1920-24)$ & $18,978.59$ & $137,521.85$ & $-829,789.37$ & $939,604.30$ \\
Cohort 2 & $(1925-29)$ & $38,664.14$ & $147,334.80$ & $-812,699.00$ & $774,916.04$ \\
Cohort 3 & $(1930-34)$ & $57,203.87$ & $156,680.32$ & $-882,038.01$ & $972,523.28$ \\
Cohort 4 & $(1935-39)$ & $80,977.46$ & $154,844.13$ & $-841,090.00$ & $1,012,689.63$ \\
Cohort 5 & $(1940-44)$ & $71,406.68$ & $144,317.71$ & $-720,594.35$ & $976,522.63$ \\
Cohort 6 & $(1945-49)$ & $62,327.43$ & $124,557.32$ & $-857,149.00$ & $879,901.97$ \\
Cohort 7 & $(1950-54)$ & $63,391.69$ & $112,468.06$ & $-853,257.62$ & $885,321.99$ \\
Cohort 8 & $(1955-59)$ & $60,046.07$ & $112,634.54$ & $-839,567.01$ & $826,382.70$ \\
Cohort 9 & $(1960-64)$ & $55,879.52$ & $115,773.56$ & $-808,343.34$ & $1,001,126.64$ \\
\hline
\end{tabular}

\section{Saving Rate}

\begin{tabular}{lrr}
\hline \multicolumn{2}{c}{ Birth Year } & \multicolumn{1}{c}{ MEAN } \\
\hline Cohort 1 & $(1920-24)$ & 7.37 \\
Cohort 2 & $(1925-29)$ & 12.08 \\
Cohort 3 & $(1930-34)$ & 15.23 \\
Cohort 4 & $(1935-39)$ & 19.22 \\
Cohort 5 & $(1940-44)$ & 17.31 \\
Cohort 6 & $(1945-49)$ & 16.63 \\
Cohort 7 & $(1950-54)$ & 18.35 \\
Cohort 8 & $(1955-59)$ & 18.42 \\
Cohort 9 & $(1960-64)$ & 17.82 \\
\hline
\end{tabular}




\section{Table 4 Analysis of Variance}

\section{Saving Rate against Cohort and Year}

\begin{tabular}{c|rrrrr} 
& Number of obs & $=110194$ & Root MSE & \multicolumn{1}{c}{$=49.3083$} \\
\hline Source & \multicolumn{1}{c}{ Partial SS } & \multicolumn{1}{c}{ df } & \multicolumn{1}{c}{ MS } & F & Prob > F \\
\hline Model & $7,419,673.47$ & 10 & $741,967.35$ & 305.19 & 0.0000 \\
Cohort & $7,416,192.81$ & 8 & $927,024.10$ & 381.31 & 0.0000 \\
Year & $18,930.43$ & 2 & $9,465.21$ & 3.89 & 0.02 \\
Residual & $267,875,168.00$ & 110,183 & $2,431.18$ & & \\
\hline Total & $275,294,841.00$ & 110,193 & $2,498.30$ & & \\
\hline
\end{tabular}

\section{Regression Result}

\begin{tabular}{|c|c|c|c|}
\hline $\begin{array}{l}\text { Number of obs } \\
\text { F( 10,110183) } \\
\text { Prob > F }\end{array}$ & $\begin{array}{l}=110194 \\
=305.19 \\
=0\end{array}$ & $\begin{array}{l}\text { R-squared } \\
\text { Adj R-squared } \\
\text { Root MSE }\end{array}$ & $\begin{array}{l}=0.027 \\
=0.0269 \\
=49.307\end{array}$ \\
\hline Source & $\overline{S S}$ & $\overline{d f}$ & $\overline{M S}$ \\
\hline Model & $7,419,673.47$ & 10 & $741,967.35$ \\
\hline Residual & $267,875,168.00$ & 110,183 & $2,431.18$ \\
\hline Total & $275,294,841.00$ & 110,193 & $2,498.30$ \\
\hline & Coef. & Std. Err. & $\mathrm{t}$ \\
\hline $\begin{array}{l}\text { Constant } \\
\text { Cohort }\end{array}$ & 13.8504 & 0.6262 & 22.1190 \\
\hline 1 & -30.3530 & 0.9142 & -33.2010 \\
\hline 2 & -19.8734 & 0.8221 & -24.1750 \\
\hline 3 & -9.7254 & 0.7843 & -12.4000 \\
\hline 4 & -0.4566 & 0.7590 & -0.6020 \\
\hline 5 & -0.7512 & 0.7315 & -1.0270 \\
\hline 6 & -0.6764 & 0.7179 & -0.9420 \\
\hline 7 & 0.3437 & 0.7229 & 0.4750 \\
\hline 8 & 0.0212 & 0.7658 & 0.0280 \\
\hline 9 & (dropped) & & \\
\hline Year & & & \\
\hline 1984 & 0.4281 & 0.3753 & 1.1410 \\
\hline 1989 & -0.6102 & 0.3554 & -1.7170 \\
\hline 1994 & (dropped) & & \\
\hline
\end{tabular}




\section{Table 5 Decomposition of Analysis of Variance}

Saving Rate against cohort (1984-94)

\begin{tabular}{|c|c|c|c|c|c|}
\hline & Number of obs & $=110194$ & Root MSE & $=49.3083$ & \\
\hline Source & Partial SS & $\mathrm{df}$ & MS & $\bar{F}$ & Prob $>F$ \\
\hline Model & $7,400,743.04$ & 8 & $925,092.88$ & 380.49 & 0.0000 \\
\hline Cohort 1 & $2,681,494.04$ & 1 & $2,681,494.04$ & $1,102.90$ & 0.0000 \\
\hline Cohort 2 & $1,431,715.40$ & 1 & $1,431,715.40$ & 588.87 & 0.0000 \\
\hline Cohort 3 & $374,276.74$ & 1 & $374,276.74$ & 153.94 & 0.0000 \\
\hline Cohort 4 & 530.46 & 1 & 530.46 & 0.22 & 0.6404 \\
\hline Cohort 5 & $1,920.96$ & 1 & $1,920.96$ & 0.79 & 0.3741 \\
\hline Cohort 6 & $1,637.27$ & 1 & $1,637.27$ & 0.67 & 0.4119 \\
\hline Cohort 7 & 790.73 & 1 & 790.73 & 0.33 & 0.5685 \\
\hline Cohort 8 & 7.28 & 1 & 7.28 & 0.00 & 0.9564 \\
\hline Cohort 9 & 0.00 & 0 & & & \\
\hline Residual & $267,894,098.00$ & 110,185 & $2,431.31$ & & \\
\hline Total & $275,294,841.00$ & 110,193 & $2,498.30$ & & \\
\hline
\end{tabular}

\section{Saving Rate against cohort (1984)}

\begin{tabular}{|c|c|c|c|c|c|}
\hline & Number of obs & $=32202$ & Root MSE & $=39.7704$ & \\
\hline Source & Partial SS & $\mathrm{df}$ & MS & $\mathrm{F}$ & Prob > F \\
\hline Model & $591,055.91$ & 8 & $73,881.99$ & 46.71 & 0.00 \\
\hline Cohort 1 & $78,289.80$ & 1 & $78,289.80$ & 49.50 & 0.00 \\
\hline Cohort 2 & 902.85 & 1 & 902.85 & 0.57 & 0.45 \\
\hline Cohort 3 & 748.84 & 1 & 748.84 & 0.47 & 0.49 \\
\hline Cohort 4 & 515.80 & 1 & 515.80 & 0.33 & 0.57 \\
\hline Cohort 5 & $4,014.32$ & 1 & $4,014.32$ & 2.54 & 0.11 \\
\hline Cohort 6 & $3,929.58$ & 1 & $3,929.58$ & 2.48 & 0.12 \\
\hline Cohort 7 & 611.96 & 1 & 611.96 & 0.39 & 0.53 \\
\hline Cohort 8 & $1,536.82$ & 1 & $1,536.82$ & 0.97 & 0.32 \\
\hline Cohort 9 & 0.00 & 0 & & & \\
\hline Residual & $50,919,054.80$ & 32,193 & $1,581.68$ & & \\
\hline Total & $51,510,110.70$ & 32,201 & $1,599.64$ & & \\
\hline
\end{tabular}

\section{Saving Rate against cohort (1989)}

\begin{tabular}{c|rrrrr}
\multicolumn{1}{c}{ Number of obs } & r 37311 & \multicolumn{2}{c}{ Root MSE } & $=56.5506$ & \\
\hline Source & \multicolumn{1}{c}{ Partial SS } & df & \multicolumn{1}{c}{ MS } & \multicolumn{1}{c}{ F } & Prob > F \\
\hline Model & $2,533,497.45$ & 8 & $316,687.18$ & 99.03 & 0.00 \\
Cohort 1 & $680,710.30$ & 1 & $680,710.30$ & 212.86 & 0.00 \\
Cohort 2 & $356,944.14$ & 1 & $356,944.14$ & 111.62 & 0.00 \\
Cohort 3 & $6,842.06$ & 1 & $6,842.06$ & 2.14 & 0.14 \\
Cohort 4 & $17,409.86$ & 1 & $17,409.86$ & 5.44 & 0.02 \\
Cohort 5 & $4,147.25$ & 1 & $4,147.25$ & 1.30 & 0.25 \\
Cohort 6 & $46,627.71$ & 1 & $46,627.71$ & 14.58 & 0.00 \\
Cohort 7 & $38,805.49$ & 1 & $38,805.49$ & 12.13 & 0.00 \\
Cohort 8 & $6,068.27$ & 1 & $6,068.27$ & 1.90 & 0.17 \\
Cohort 9 & 0.00 & 0 & & & \\
Residual & $119,290,482.00$ & 37,302 & $3,197.96$ & & \\
\hline Total & $121,823,979.00$ & $37,310.00$ & $3,265.18$ & & \\
\hline
\end{tabular}

\section{Saving Rate against cohort (1994)}

\begin{tabular}{|c|c|c|c|c|c|}
\hline & Number of obs & $=40681$ & Root MSE & $=48.2852$ & \\
\hline Source & Partial SS & $\overline{\mathrm{df}}$ & MS & $\bar{F}$ & Prob > F \\
\hline Model & $7,132,082.83$ & 8 & $891,510.35$ & 382.38 & 0.00 \\
\hline Cohort 1 & $2,027,815.70$ & 1 & 2,027,815.70 & 869.76 & 0.00 \\
\hline Cohort 2 & 1,890,821.82 & 1 & $1,890,821.82$ & 811.00 & 0.00 \\
\hline Cohort 3 & $1,359,567.47$ & 1 & $1,359,567.47$ & 583.14 & 0.00 \\
\hline Cohort 4 & $4,638.21$ & 1 & $4,638.21$ & 1.99 & 0.16 \\
\hline Cohort 5 & 3.32 & 1 & 3.32 & 0.00 & 0.97 \\
\hline Cohort 6 & $36,154.09$ & 1 & $36,154.09$ & 15.51 & 0.00 \\
\hline Cohort 7 & $1,607.83$ & 1 & $1,607.83$ & 0.69 & 0.41 \\
\hline Cohort 8 & $10,605.99$ & 1 & $10,605.99$ & 4.55 & 0.03 \\
\hline Cohort 9 & 0.00 & 0 & & & \\
\hline Residual & $94,825,187.90$ & 40,672 & 2,331.46 & & \\
\hline Total & $101,957,271.00$ & $40,680.00$ & $2,506.32$ & & \\
\hline
\end{tabular}




\section{Table 6 The Crude Ratio between Mandatory and Discretionary Savings (\%)}

\begin{tabular}{|c|c|c|c|c|c|}
\hline & & 1984 & 1989 & 1994 & 1984-94 \\
\hline Cohort 1 & $(1920-24)$ & -315.55 & -434.00 & $6,510.88$ & -779.75 \\
\hline Cohort 2 & (1925-29) & -30.14 & -277.11 & $-1,646.01$ & -264.71 \\
\hline Cohort 3 & (1930-34) & 25.82 & -7.42 & -270.87 & -48.25 \\
\hline Cohort 4 & (1935-39) & 32.34 & 24.55 & 14.92 & 21.34 \\
\hline Cohort 5 & $(1940-44)$ & 26.96 & 31.95 & 27.34 & 28.48 \\
\hline Cohort 6 & $(1945-49)$ & 25.24 & 22.81 & 32.68 & 27.36 \\
\hline Cohort 7 & (1950-54) & 25.57 & 21.81 & 24.12 & 23.56 \\
\hline Cohort 8 & (1955-59) & 32.54 & 26.57 & 23.37 & 24.88 \\
\hline Cohort 9 & (1960-64) & 11.79 & 31.98 & 28.09 & 28.38 \\
\hline \multicolumn{2}{|c|}{ Average } & 8.66 & -9.20 & -14.36 & -7.79 \\
\hline
\end{tabular}

Source: National Survey of Family Income and Expenditure, 1984,1989, and 1994.

Note: The mandatory savings are defined as a difference between public pension contributions and its benefits, i.e. net public pension contributions. Those aged above 60 receive public pension benefits so that mandatory savings become negative. 


\section{Fig.1 Age Profile of Saving Rate}

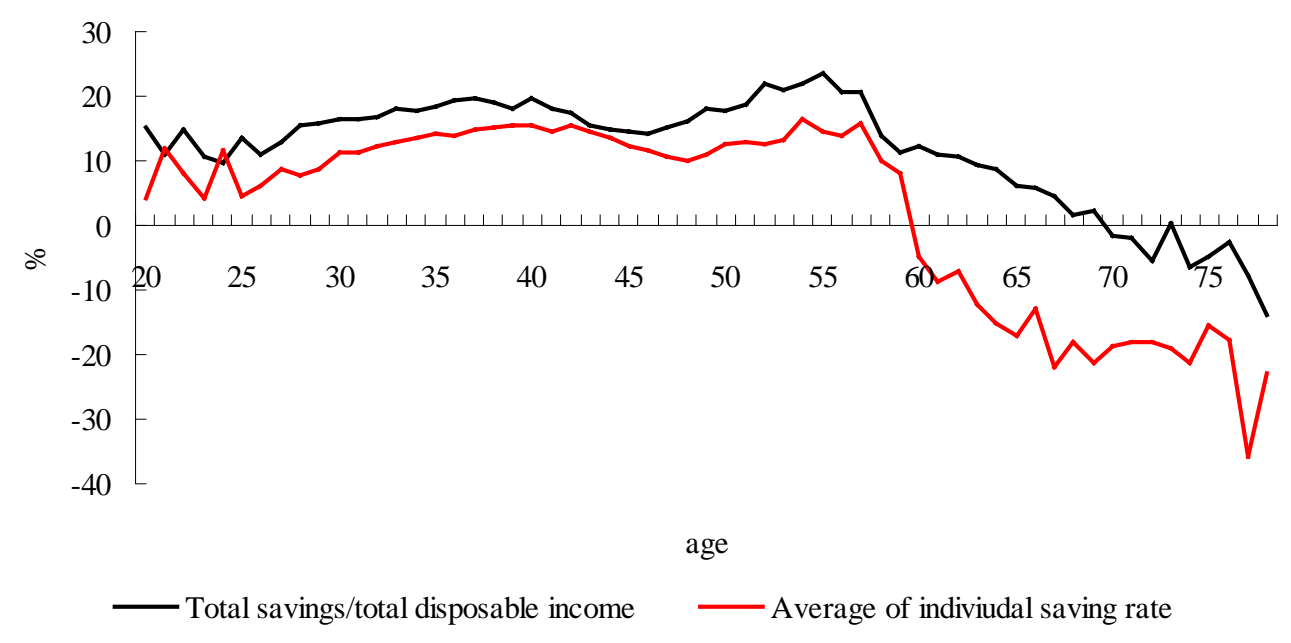

Note: All samples in the 1984, 1989 and 1994 NSFIE are pooled. 
Fig.2 Monthly Saving Rate by Cohort

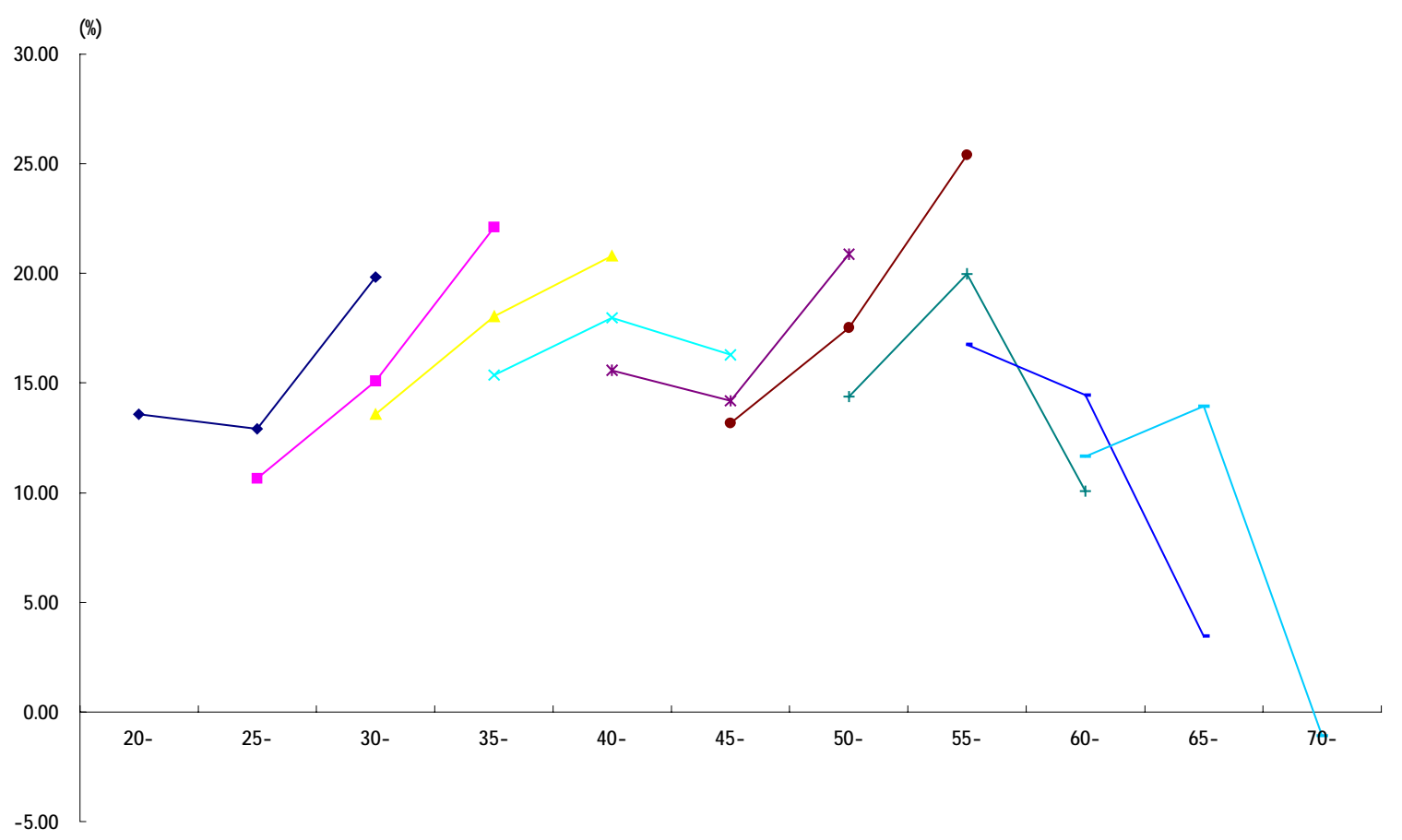

Fig.3 Social Security Wealth over Life Cycle

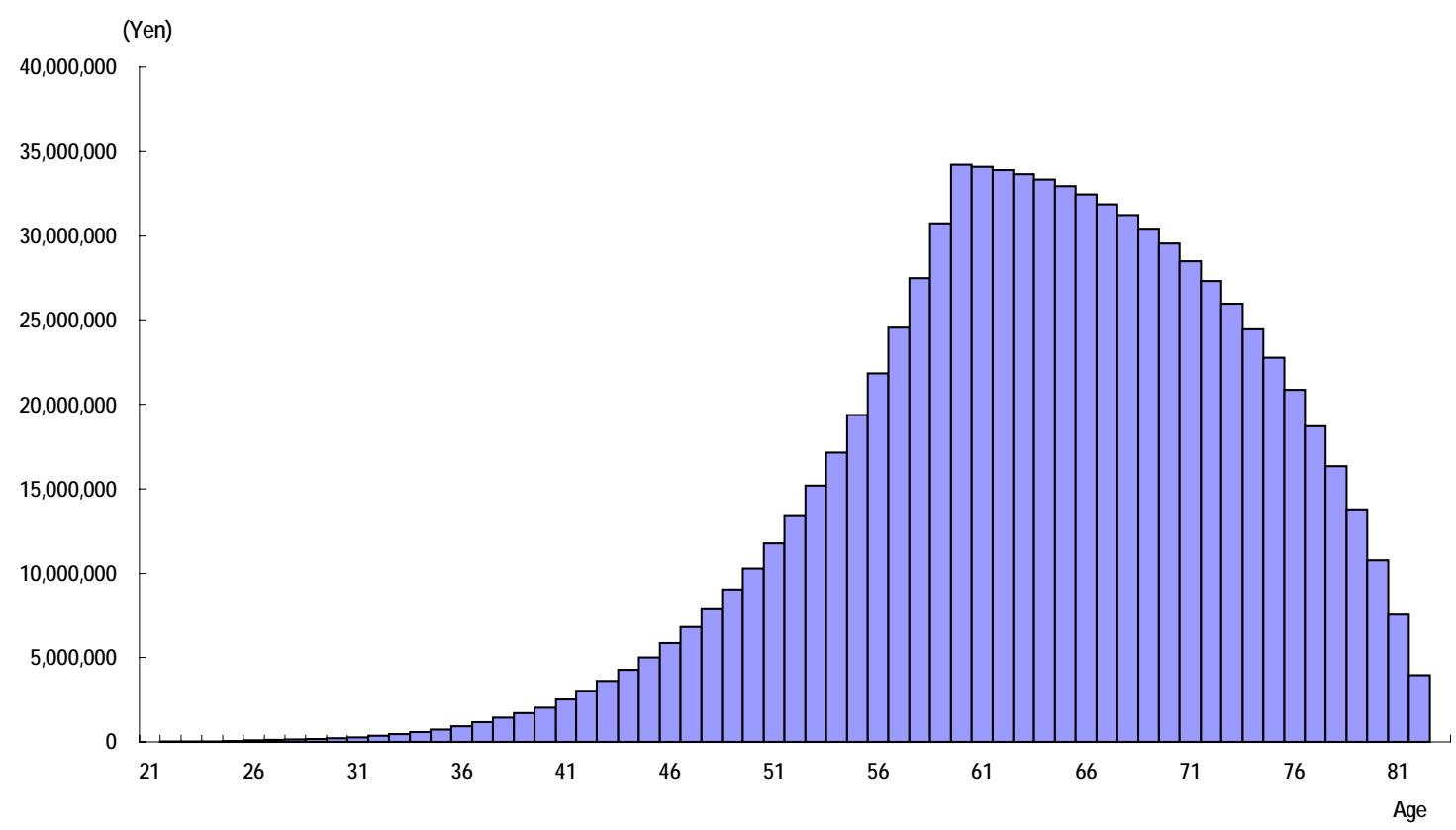

